\title{
Development of Testing Platform and Comparison Studies for Wood Nondestructive Testing
}

\author{
Jian Li, ${ }^{1,2}$ Yiming Fang, ${ }^{1,2}$ Jiyong Tang, ${ }^{3}$ Hailin Feng, ${ }^{1,2}$ and Xiongwei Lou ${ }^{1,2}$ \\ ${ }^{1}$ School of Information Engineering, Zhejiang Agricultural \& Forestry University, Linian 311300, China \\ ${ }^{2}$ Key Laboratory of Forestry Intelligent Monitoring and Information Technology of Zhejiang Province, Linian 311300, China \\ ${ }^{3}$ School of Electrical Engineering and Information, Sichuan University, Chengdu 610065, China \\ Correspondence should be addressed to Yiming Fang; ilone_fang@126.com
}

Received 6 June 2016; Accepted 14 July 2016

Academic Editor: Ephraim Suhir

Copyright (c) 2016 Jian Li et al. This is an open access article distributed under the Creative Commons Attribution License, which permits unrestricted use, distribution, and reproduction in any medium, provided the original work is properly cited.

\begin{abstract}
Stress wave based techniques have been developed for evaluating the quality of the wooden materials nondestructively. However the existing techniques have some shortcomings due to the significant variation of the wood properties and are now in need of updating. There are also stress wave based instruments which have been widely used for nondestructive testing of wood. But most of them are inflexible and unsuitable for the tentative studies. This paper proposed and implemented a wood nondestructive testing platform based on NI virtual instrument. Three wood nondestructive testing methods, including peak time interval measurement, cross-correlation, and spectrum analysis, were also tested on this platform with serious decay sample, early decay sample, and defect-free sample. The results show that new methods can be verified easily and the researches of wood nondestructive testing will be accelerated with the designed platform.
\end{abstract}

\section{Introduction}

Wood nondestructive testing technology can predict the wood internal condition without destruction and has been utilized to detect the mechanical properties of standing trees [1] or the decay and holes of wood [2]. By far, many wood nondestructive testing techniques have been studied, such as X-ray detection [3], ultrasonic [4], mechanical stress [5], and acoustic emission [6].

Among them, the stress wave detection method attracts more attention due to its insensitivity to the shape and the size of the wood, harmlessness to human body, and easiness to use [7]. Ross et al. showed that the flight time of the stress wave can be used to predict whether the wood was defective [8]. Li et al. investigated the stress wave velocity pattern in the cross sections of black cherry trees and then employed this pattern to detect the internal defect [9]. All of the above work have proven the effectiveness of stress wave technique for the detection of wood defect.

During the past decades, many commercial instruments sprang up, such as Fakopp TreeSonic acoustic device [10] and
Model 239A Stress Wave Timer [11]. Other instruments have also been reported $[12,13]$. However, the functions of those instruments are always predefined by manufacturers and cannot be altered to satisfy the user's different requirements. In fact, the propagation of the stress wave is quite complex due to the anisotropy and inhomogeneity of the wood material, and most instruments like the above-mentioned cannot satisfy the practical requirement due to the unobtrusive precisions. Therefore, efforts should be made to investigate more advanced signal processing methods after the stress wave signals are collected. So a flexible testing platform is needed to meet this demand in the pilot phase of the tentative study.

The NI virtual instrument has a major advantage that the hardware and the software can be redesigned or improved easily and quickly to meet the variable demand [14]. In this study, we design a wood nondestructive testing platform using the NI virtual instrument. Subsequently, we verify the testing platform by comparing three methods which have potentialities to be applied to wood nondestructive testing in the future. 


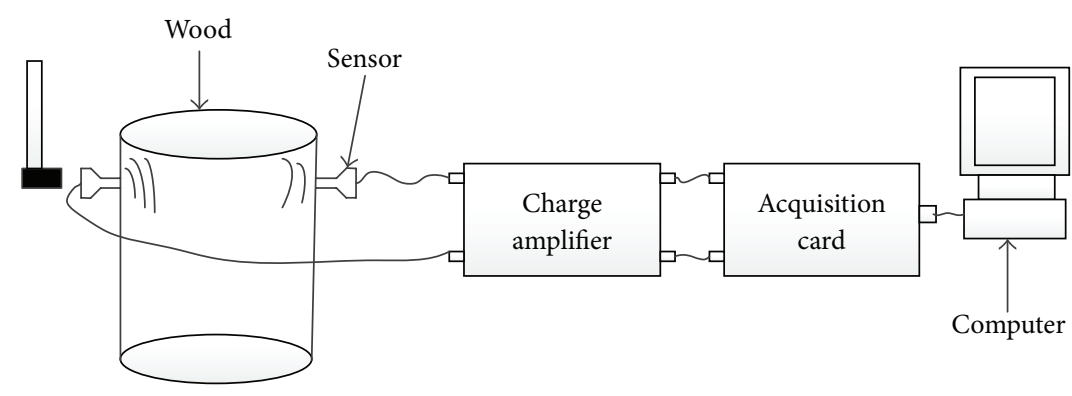

FIgURE 1: The structure of hardware system.

\section{Platform for Nondestructive Testing of Wood}

2.1. Hardware Setup. The hardware system of the testing platform was composed of piezoelectric acceleration sensors, charge amplifier, data acquisition card, and computer. The structure can be illustrated in Figure 1. The piezoelectric acceleration sensors were employed to sense the stress wave and fixed on the wood by a nail. The output signal of the sensor was amplified by the charge amplifier, and then the signal was input into NI data acquisition card. Finally, the analogy signal was converted into digital form and sent to computer through universal serial bus (USB).

It is very important to select reasonable sensors in the implementation of nondestructive testing wood. A good example is that the frequency band should be wider than that of the stress wave. In this work, the piezoelectric acceleration sensors were selected from Beidaihe Rand Technology Co. Ltd., which has good performance with its wide broadband, low impedance output, antijamming ability, and low noise. And the matched charge amplifier was also manufactured by this company.

The Data Acquisition Equipment was selected in terms of the performance in collection efficiency, reliability of the data collection, and convenience of the field use. The equipment NI USB-6259 is a multifunction DAQ module with a highspeed USB interface, which can provide high accuracy at high-speed sampling. The Plug and Play function also makes it very easy to install the hardware system. The MX driver and measurement services software of NI-DAQ provide a simple configuration and programming interface. Together with the DAQ Assistant, NI USB-6259 can help users to save the development time.

2.2. Implementation of Signal Acquisition and Data Storage. In this work, the flexible testing platform provides a variety of analyzing methods. What is more, the system can be easily redesigned with functions altered. Therefore, we employed the PC-DAQ which, based on Graphical Programming, can facilitate the hierarchical and modular design.

As mentioned above, both the maximum amplitude and the maximum frequency of the output signal were within the ranges of the sensors. Therefore, we connected the amplifier to the ports of the DAQ card directly. Ai0 and Ail were set at the sampling channels. The amplitude range was $-10 \mathrm{~V}$ to
$10 \mathrm{~V}$. The differential mode was selected. The sampling frequency was $500 \mathrm{KHz}$.

The signal can be saved in many file formats, such as excel file, text file, and binary file. Among them, the binary file has the fastest accessing speed and can meet the requirement of high-speed data acquisition. Besides, it holds high performance on compatibility, which enables the data to be analyzed in other software. Therefore, all the signals recorded were saved as binary files.

The Labview code for implementing signal acquisition and data storage is shown in Figure 2.

\section{Tentative Methods for Nondestructive Testing of Wood}

In the earlier studies, the flight time (or the propagation velocity) of the stress wave has usually been used to predict the internal conditions of the wood, such as Young's modulus [15] and internal decay [16]. Therefore, it plays a key role in wood nondestructive testing to measure the propagation time of the stress wave accurately. In this study, we employed peak time interval measurement method and cross-correlation method to accurately obtain propagation time of stress wave in wood.

The spectral analysis has also been proven to be one of the most effective techniques for detecting internal defect of wood nondestructively. Yu et al. evaluated the wood by analyzing the frequency spectrum of stress wave captured by transmitting and receiving sensors on the wood. The result showed that higher frequency components of the stress wave will be attenuated more quickly in wood, and the stress wave will be attenuated more quickly in decay wood than normal wood [17].

3.1. Peak Time Interval Measurement Method. In this work, the time interval between the first peak of transmitted signal and received signal was used as the propagating time of stress wave in the wood. However, there are many problems which hinder the implementation of this method. For example, the peak is prone to misjudgment due to the impulse noise and the weak amplitude of the signal. Therefore, the Median Filtering VI, provided by the Labview software, was firstly employed to reduce the impulse noise. Then, a Peak Detector VI was developed to locate the peaks. The threshold was set as $0.2 \mathrm{~V}$. Finally, the appearing times of the peaks were sent to 


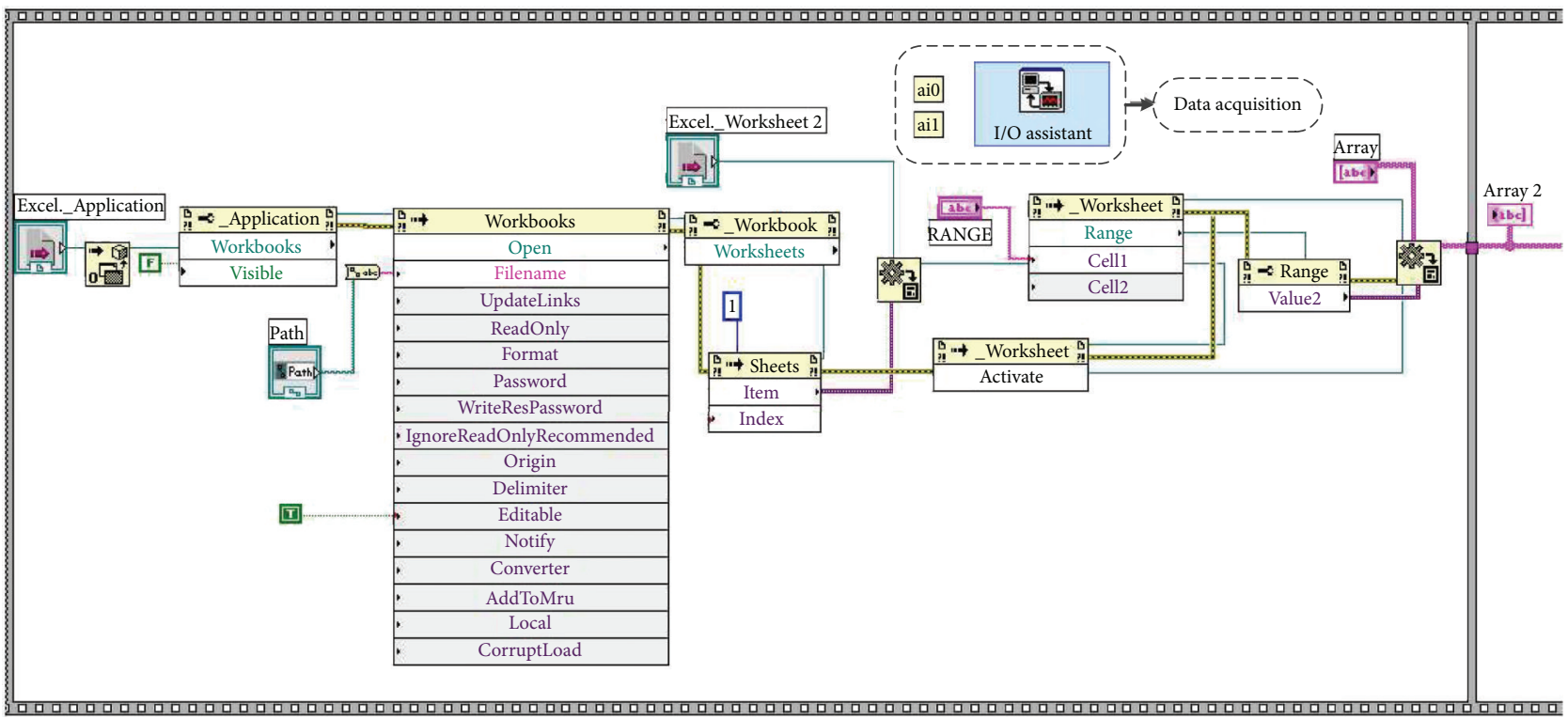

FIGURE 2: Labview code of signal acquisition and data storage.

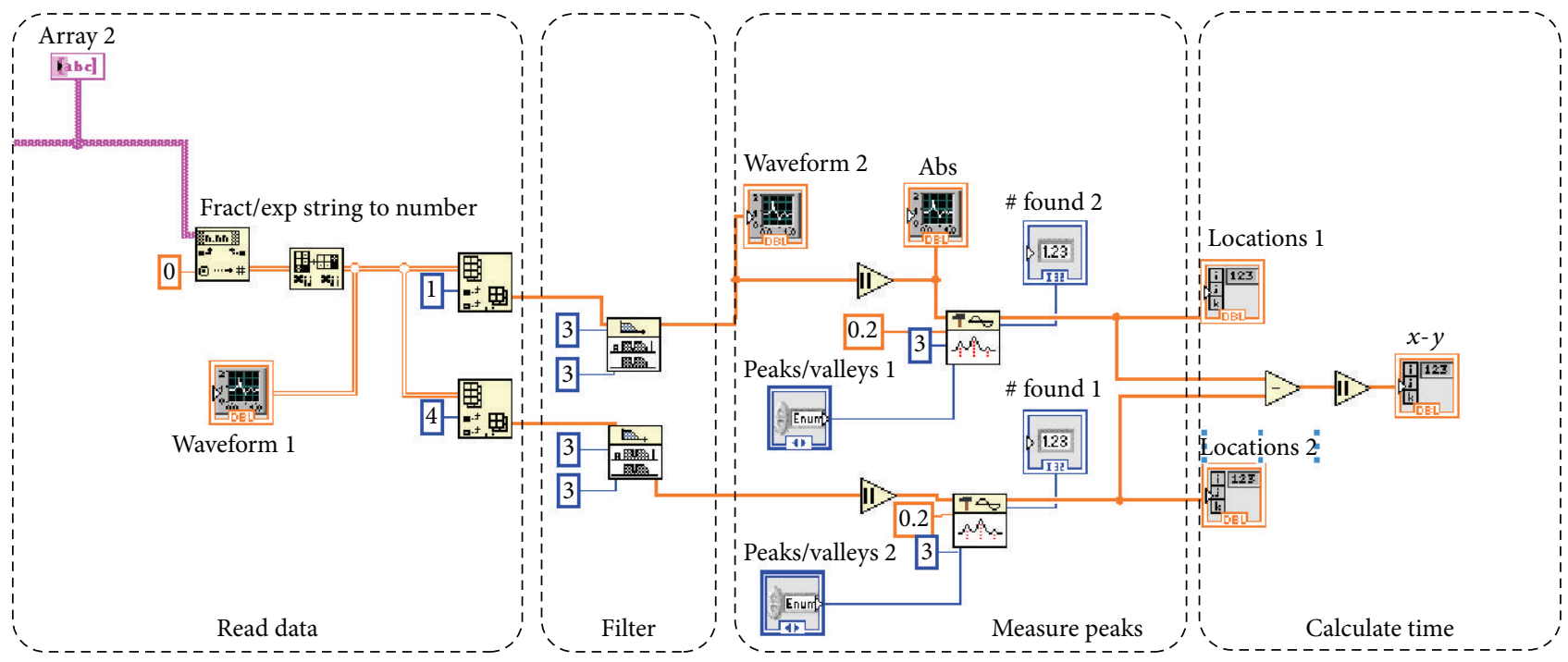

FIgURE 3: Labview code of peak time interval measurement.

the Subtraction VI and the flight time of the stress wave can be computed. Figure 3 illustrated the Labview code of flight time measurement.

3.2. Cross-Correlation Method. Cross-correlation method was often used to estimate the signal propagating time [18]. An accurate evaluation can be obtained especially when the two signals are very similar.

Assuming that the transmitted signal and the received signal are $x_{1}(k)$ and $x_{2}(k)$, respectively, where $k$ is the sampling index. The flight time $\widehat{\tau}$ is given by the following function:

$$
\widehat{\tau}=\arg \max _{m}\left\{R_{x y}(m)\right\},
$$

where $R_{x y}(m)$ is the cross-correlation function of $x_{1}(k)$ and $x_{2}(k)$ and can be expressed as follows:

$$
R_{x y}(m)=\frac{1}{N-m} \sum_{k=0}^{N-m-1} x_{1}(k) x_{2}(k-m),
$$

where $N$ defines the length of both $x_{1}(k)$ and $x_{2}(k)$.

Because the noise will diminish the similarity of two stress wave signals, we firstly employed the IIR filter VI to eliminate noise. The pass-band used here is $100 \mathrm{~Hz}$ to $5 \mathrm{KHz}$, which is the same as in the literature [17]. Subsequently, the crosscorrelation VI was used to compute the cross-correlation value of the two input signals. Finally, the Statistics Express VI was used to locate the maximal correlation value. The flight 


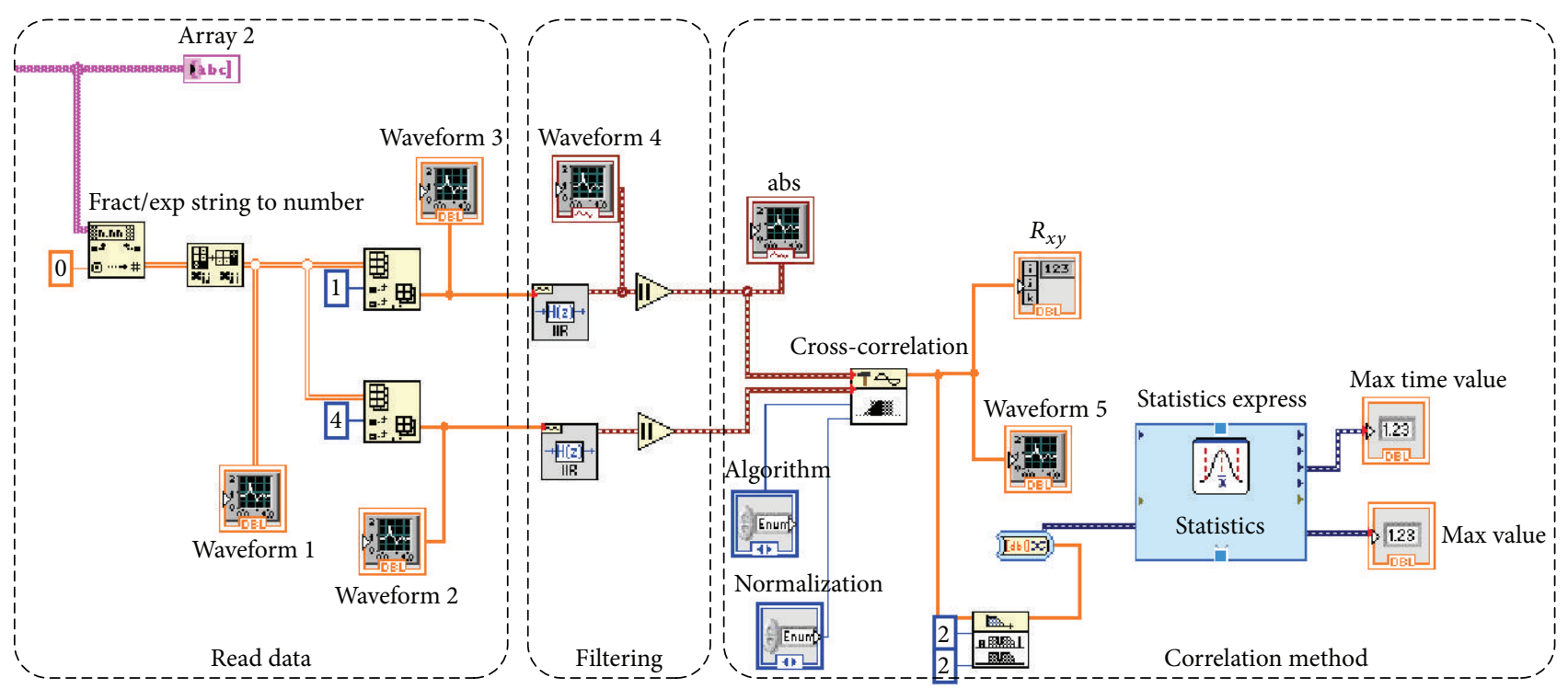

FIGURE 4: Labview code of correlation method.

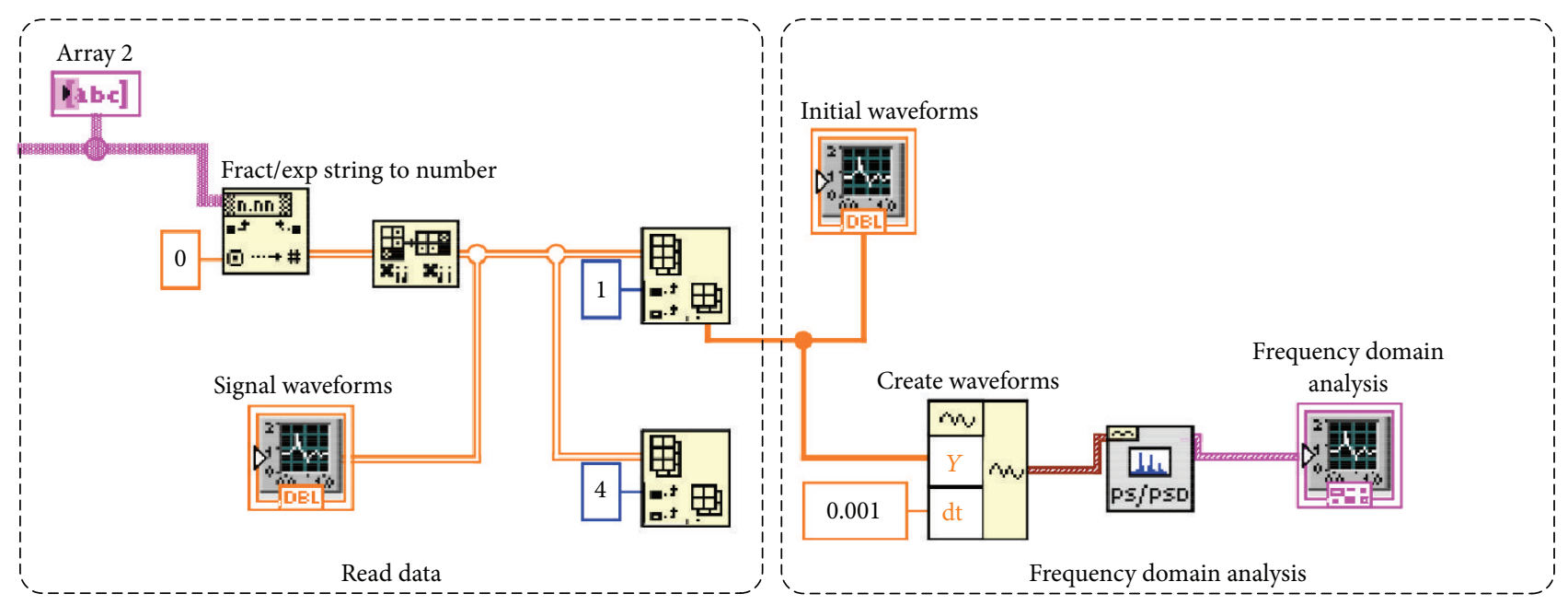

FIGURE 5: Labview code of spectrum analysis.

time was then computed using the location of the maximal correlation. Figure 4 depicts the implementation of this method.

3.3. Analysis of Stress Wave Signal in Frequency Domain. At first, the Create Waveforms VI was developed to cut the stress wave signal data into continuous segments, with the duration being $1 \mathrm{~ms}$. Then the Power Spectrum VI was employed to transform the stress wave signal into the frequency domain. The Labview implementation is shown in Figure 5.

\section{Experiments and Results}

To test the performance of the developed platform, experiments were carried out on three Camphor samples, as shown in Figure 6. The average diameter of the wood samples was $30 \mathrm{~cm}$ and the average height was $40 \mathrm{~cm}$. The Camphor samples were characterized by different sizes of defects. The first had serious decay area. The second one had early decay area and the last one was a sound wood.

Typical stress waves are shown in Figure 7. The blue dashed line plots the transmitted signal and the red solid line corresponds to the received signal.

4.1. Results of Time Domain Analysis. The peak time interval measurement method and the cross-correlation method mentioned above were carried on with our platform. Table 1 lists the flight time obtained from the three samples using different methods. In order to reduce the influence of some random factors, the flight time listed in Table 1 is the average of 10 repetitions.

It can be seen from Table 1 that the flight time obtained by two methods are very close. They are both sensitive to the 


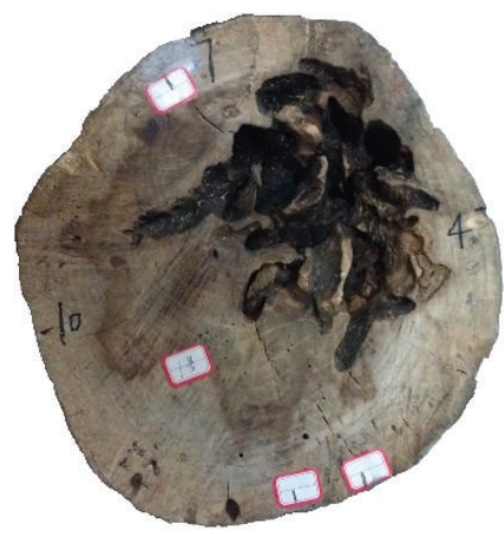

(a)

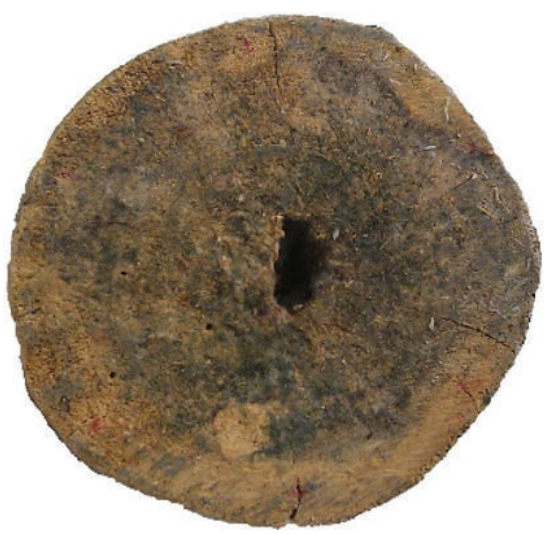

(b)

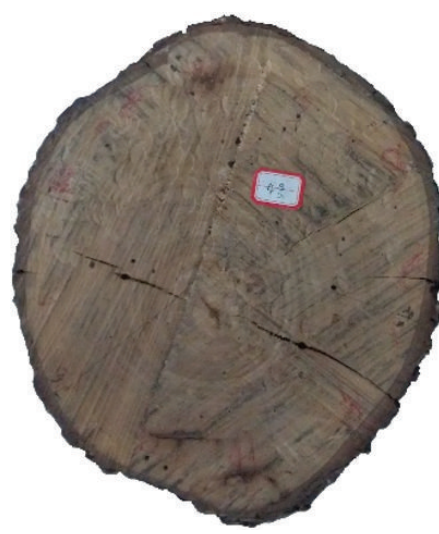

(c)

FIGURE 6: Photos of the wood samples used in this work. (a-c): (a) serious defect, (b) early defect, and (c) sound sample.

TABLE 1: Flight time obtained by two methods $(\mu \mathrm{s})$.

\begin{tabular}{lccc}
\hline & Serious defect & Early defect & Defect-free \\
\hline Peak method & 504 & 160 & 48 \\
Correlation method & 428 & 144 & 42 \\
\hline
\end{tabular}

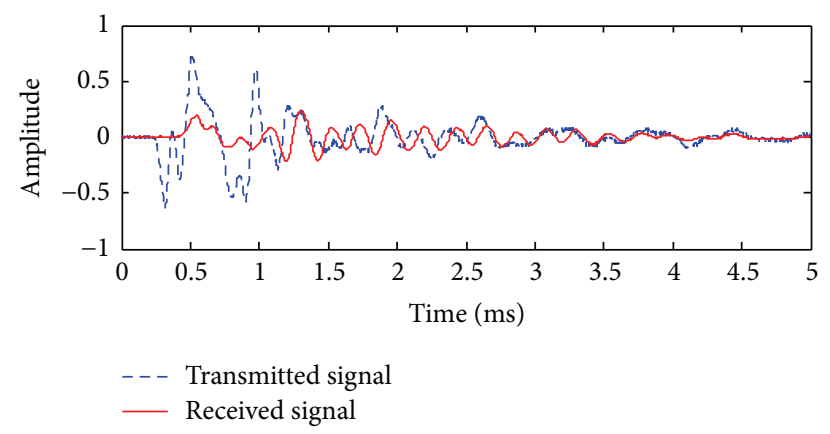

FIgURE 7: Transmitted and received signals.

degree of the defect. It took about $45 \mu$ s for stress wave to travel in the defect-free sample and approximately 3 times longer to travel in the sample with early defect. The time of flight corresponding to the seriously sample is 9 times of those in response to the sound sample. Therefore, both of the two methods have the potentiality of application in nondestructive testing of wood and further studies are needed to demonstrate their performance.

It also can be observed that the value obtained employing correlation method is a little less than that employing peak method. Literature [19] reported that current time of flight techniques provide stiffness measurements that are higher than those obtained employing other techniques. Therefore, it can be expected that the correlation method has the potential to improve the accuracy of stiffness testing employing time of flight.

4.2. Results of Frequency Domain Analysis. With the Labview code of the spectrum analysis, we transformed the signal recorded on the received sensor into frequency domain. Figure 8 shows the obtained spectra. From (a, b, c), the spectra corresponded to sample with serious defect, sample with early defect, and sound sample, respectively.

The results of stress wave signal analysis show that if the size of defect is larger the low frequency part of received stress wave is more, because the high-frequency stress wave will attenuate due to the timber defect. And the results also indicate spectra analysis method can be used to distinguish timbers with large defect, small defect, and defect-free by the frequency distribution of stress wave.

\section{Conclusion}

In this paper, we designed a wood nondestructive testing platform based on NI virtual instrument which can collect, convert, and store the stress wave data. Based on the testing platform, the performance of three methods, including peak time interval measurement method, cross-correlation method, and spectrum analysis method, was compared with each other for the nondestructive testing of wood. The hardware of the platform and the Labview codes for implementing the three methods were described in detail. The results indicated that the designed platform has the flexibility which enable the tentative ideas to be verified easily. All of the three methods have potential to be used for the nondestructive testing of wood. Timbers with large defect and small defect and that are defect-free can be distinguished.

This study proves that this platform is feasible and has a great potential in the development of new methods for detecting wood defects in the radial direction. Further research into defect detection in the longitudinal direction is recommended. Moreover, efforts will be made to investigate new methods to evaluate the mechanical behavior of the wood nondestructively with this platform.

\section{Competing Interests}

The authors declare that they have no competing interests. 


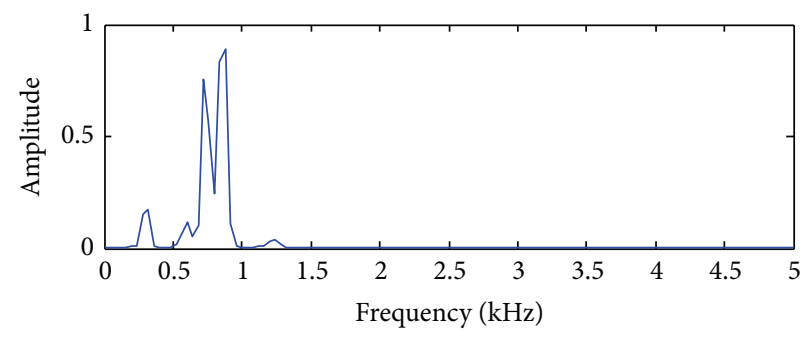

(a)

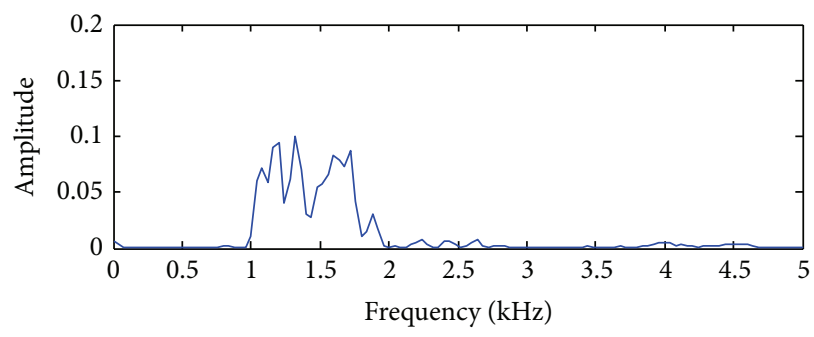

(b)

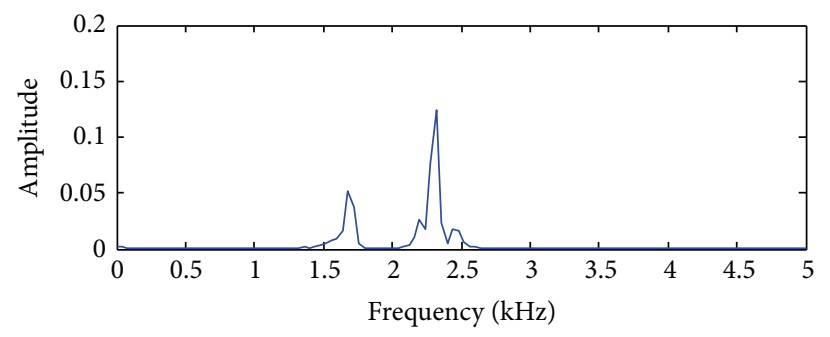

(c)

FIGURE 8: Spectra of signals recorded on different samples. (a-c): (a) sample with serious defect, (b) sample with early defect, and (c) sound sample.

\section{Acknowledgments}

This work is partially supported by the Natural Science Foundation of China (no. 61302185 and 61272313), Zhejiang Provincial Science and Technology Project (no. LQ14F020014), Key Laboratory of Forestry Intelligent Monitoring, and Information Technology Research of Zhejiang Province (no. 100151402 and 100151401). The financial support of Yiming Fang's visiting study at New Zealand Forestry Research Institute Limited (Scion) was provided by China Scholarship Council (CSC).

\section{References}

[1] C. B. Wessels, F. S. Malan, and T. Rypstra, "A review of measurement methods used on standing trees for the prediction of some mechanical properties of timber," European Journal of Forest Research, vol. 130, no. 6, pp. 881-893, 2011.

[2] C.-J. Lin, T.-T. Chang, M.-Y. Juan et al., "Stress wave tomography for the quantification of artificial hole detection in camphor trees (Cinnamomum camphora)," Taiwan Journal of Forest Science, vol. 26, no. 1, pp. 17-32, 2011.

[3] F. Longuetaud, F. Mothe, B. Kerautret et al., "Automatic knot detection and measurements from X-ray CT images of wood: a review and validation of an improved algorithm on softwood samples," Computers and Electronics in Agriculture, vol. 85, pp. 77-89, 2012.

[4] J. L. Sandoz, Y. Benoit, and L. Demay, "Wood testing using acousto-ultrasonic," in Proceedings of the 12th International Symposium on Nondestructive Testing of Wood, Sopron, Hungary, September 2000.

[5] X. Wang, F. Divos, C. Pilon, B. K. Brashaw, R. J. Ross, and R. F. Pellerin, "Assessment of decay in standing timber using stress wave timing nondestructive evaluation tools," USDA FS Forest Products Laboratory General Technical Report FPL-GTR-147,
U.S. Department of Agriculture, Forest Service, Washington, DC, USA, 2004.

[6] P. Carter, D. Briggs, R. J. Ross, and X. Wang, "Acoustic testing to enhance western forest values and meet customer wood quality needs," USDA FS Forest Products Laboratory General Technical Report PNW-GTR-642, US Department of Agriculture Forest Service, Washington, DC, USA, 2005.

[7] B. Kasal and T. Tannert, In Situ Assessment of Structural Timber, Springer, 2011.

[8] R. J. Ross, R. C. DeGroot, W. J. Nelson, and P. K. Lebow, “The relationship between stress wave transmission characteristics and the compressive strength of biologically degraded wood," Forest Products Journal, vol. 47, no. 5, pp. 89-93, 1997.

[9] G. Li, X. Wang, H. Feng, J. Wiedenbeck, and R. J. Ross, "Analysis of wave velocity patterns in black cherry trees and its effect on internal decay detection," Computers \& Electronics in Agriculture, vol. 104, no. 2, pp. 32-39, 2014.

[10] R. L. Amateis and H. E. Burkhart, "Use of the fakopp treesonic acoustic device to estimate wood quality characteristics in loblolly pine trees planted at different densities," in Proceedings of the 17th Biennial Southern Silvicultural Research Conference, Shreveport, La, USA, March 2015.

[11] R. A. Garcia, A. M. De Carvalho, J. V. De Figueiredo Latorraca, J. L. M. De Matos, W. A. Santos, and R. F. De Medeiros Silva, "Nondestructive evaluation of heat-treated Eucalyptus grandis Hill ex Maiden wood using stress wave method," Wood Science \& Technology, vol. 46, no. 1-3, pp. 41-52, 2012.

[12] J. Xiao, C. Sa, and Y. Han, "Nondestructive testing of dynamic elastic modulus of wood-based panel by the method of stress wave," in Proceedings of the 9th International Conference on Electronic Measurement \& Instruments, Beijing, China, August 2009.

[13] Y. Fang, H. Feng, J. Li, and G. Li, "A DSP based stress wave instrument for wood decay detection," International Journal of Digital Content Technology and Its Applications, vol. 5, no. 8, pp. 415-422, 2011. 
[14] Q. Wu, L. Wang, and L. Zu, "A LabVIEW-based virtual instrument system for laser-induced fluorescence spectroscopy," Journal of Automated Methods and Management in Chemistry, vol. 2011, Article ID 457156, 7 pages, 2011.

[15] M. Yamasaki and Y. Sasaki, "Determining Young's modulus of timber on the basis of a strength database and stress wave propagation velocity I: an estimation method for Young's modulus employing Monte Carlo simulation," Journal of Wood Science, vol. 56, no. 4, pp. 269-275, 2010.

[16] C.-J. Lin, Y.-H. Huang, G.-S. Huang, and M.-L. Wu, "Detection of decay damage in iron-wood living trees by nondestructive techniques," Journal of Wood Science, vol. 62, no. 1, pp. 42-51, 2016.

[17] G. X. Yu, A. Z. Zhang, B. Z. Shi, and X. G. Ruan, "Detection of timber decay by stress wave frequency spectrum," Chinese Journal of Northeast Forestry University, vol. 35, no. 10, pp. 22-25, 2007 (Chinese with English Abstract).

[18] D. Hertz and M. Azaria, "Time delay estimation between two phase shifted signals via generalized cross-correlation methods," Signal Processing, vol. 8, no. 2, pp. 235-257, 1985.

[19] X. Wang, R. J. Ross, and P. Carter, "Acoustic evaluation of wood quality in standing trees. Part I. Acoustic wave behavior," Wood and Fiber Science, vol. 39, no. 1, pp. 28-38, 2007. 


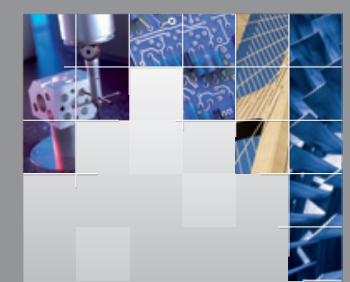

\section{Enfincering}
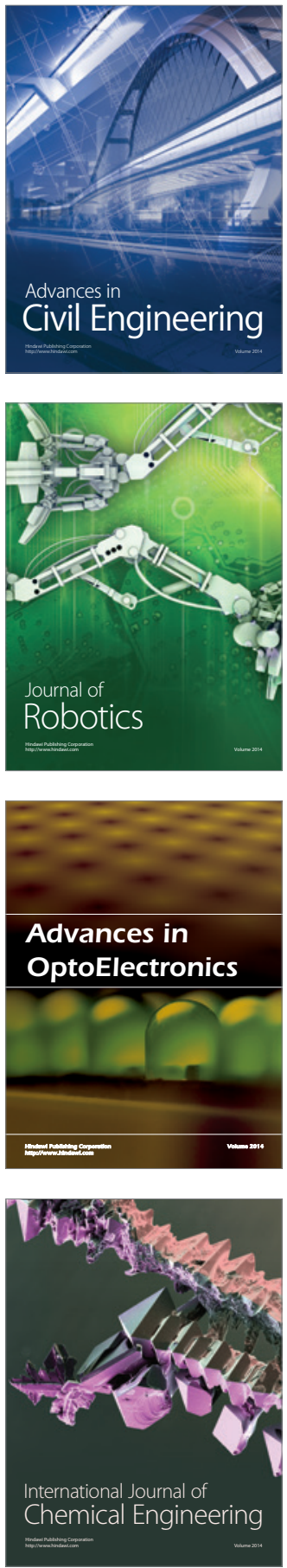

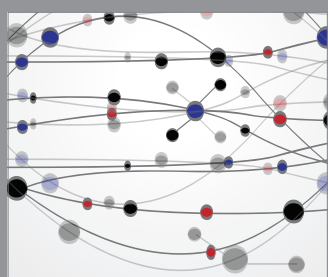

The Scientific World Journal

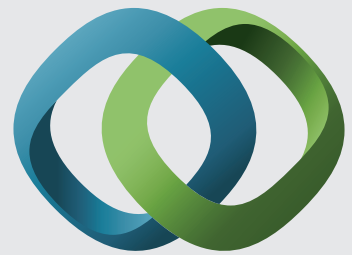

\section{Hindawi}

Submit your manuscripts at

http://www.hindawi.com
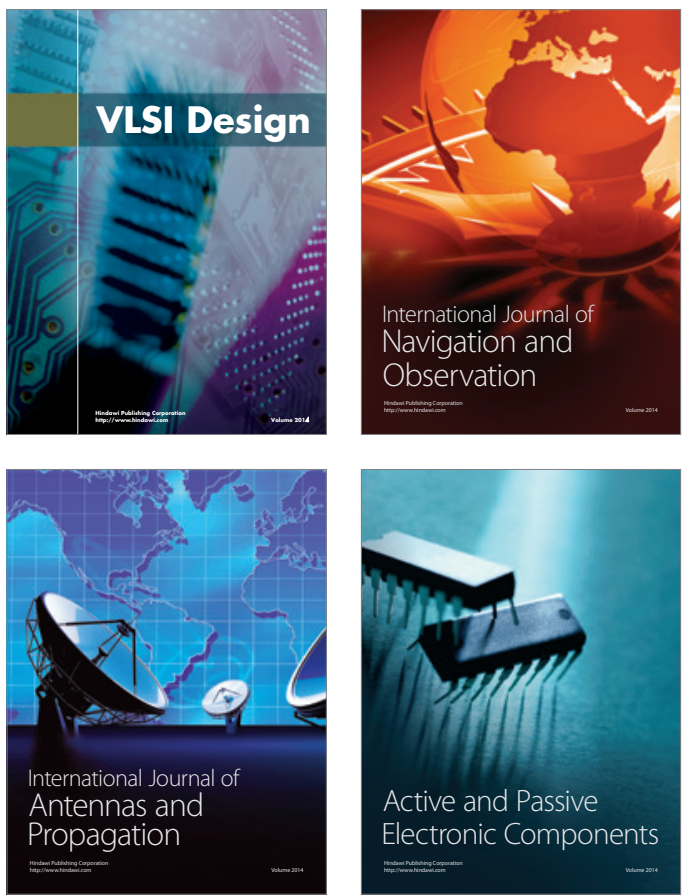
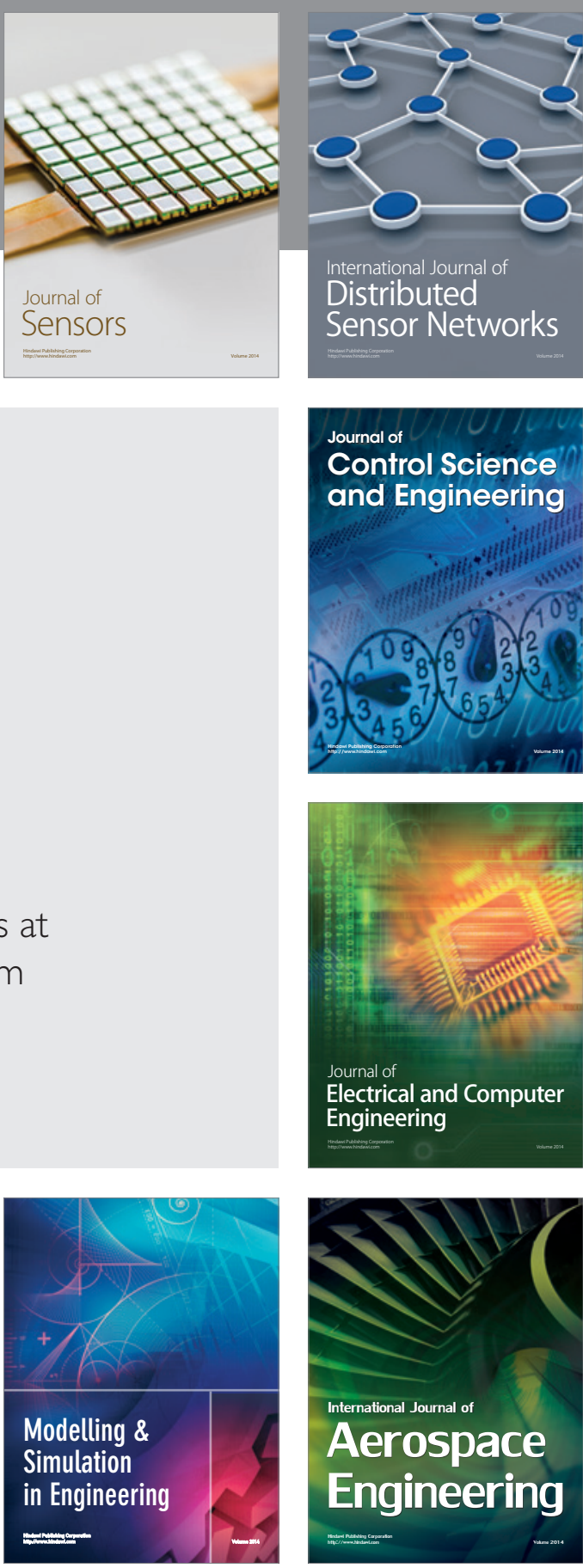

International Journal of

Distributed

Sensor Networks

Journal of

Control Science

and Engineering
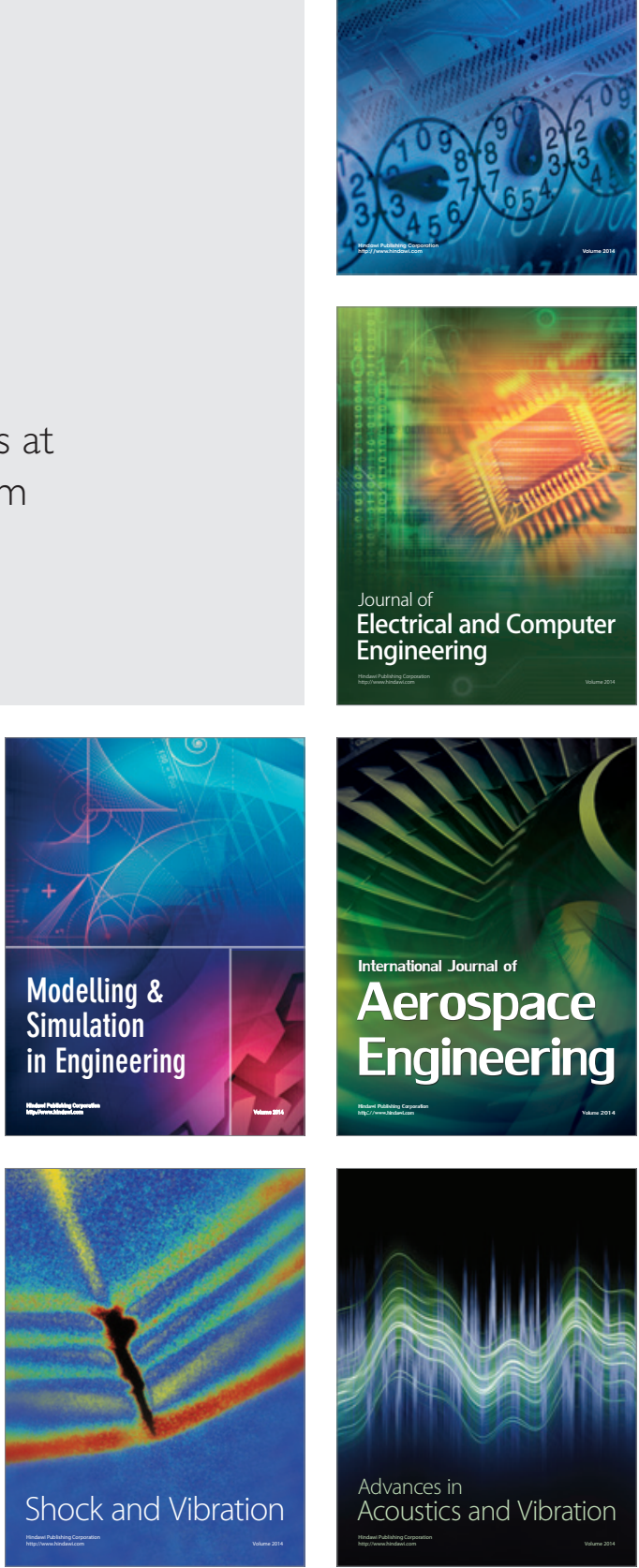